\title{
O SIGNIFICADO DA ALIMENTAÇÃO NA FAMÍLIA: UMA VISÃO ANTROPOLÓGICA
}

THE MEANING OF ALIMENTATION IN FAMILY: AN ANTHROPOLOGICAL VIEW

Geraldo Romanelli

Docente. Departamento de Psicologia e Educação. Faculdade de Filosofia, Ciências e Letras de Ribeirão Preto - USP

CoRrespondêncIA: Departamento de Psicologia e Educação. Faculdade de Filosofia, Ciências e Letras de Ribeirão Preto - USP. Av. Bandeirantes, 3900 - CEP 14040-901 - Ribeirão Preto - SP. email: geromane@ffclrp.usp.br

Romanelli G. O significado da alimentação na família: uma visão antropológica. Medicina (Ribeirão Preto) 2006; 39 (3): 333-9.

RESUMO: Fome é uma necessidade natural que deve ser satisfeita através da ingestão de alimentos para assegurar a produção e reprodução da existência humana. No entanto, se o ato de saciar a fome é natural e universal, as práticas alimentares, também universais, não são naturais, mas situam-se na esfera da cultura, vale dizer, no campo dos sistemas simbólicos. Em torno da comensalidade, cada sociedade elabora um complexo sistema de regras dietéticas fundadas no senso comum, em preceitos religiosos e no conhecimento médico, que criam interdições para excluir do cardápio alimentos simbolicamente classificados como nocivos e perigosos para a saúde. Trabalhos antropológicos têm mostrado a diversidade das formas de produção, processamento e consumo de alimentos, que não são atos solitários, mas constituem atividades sociais, e o modo como as sociedades constroem representações sobre si próprias, definindo sua identidade em relação a outras sociedades, através de seus hábitos culinários. Este trabalho examina o modo como a população de baixa renda articula elementos simbólicos provenientes de várias fontes para organizar regras dietéticas que passam a constituir indicadores culturais através dos quais os alimentos são categorizados em apropriados ou nocivos para o consumo. A comida é uma categoria que estabelece fronteiras entre a identidade da população pobre, que enfrenta dificuldades para prover a alimentação, e a identidade daqueles cuja cozinha é rica e variada, e a dos muito pobres, que passam fome.

Descritores: Alimentação. Dietética; regras. Família de Baixa Renda.

\section{1- ALIMENTAÇÃO E DIVERSIDADE CUL- TURAL}

Múltiplos aspectos da alimentação têm estado bastante presentes na mídia brasileira e uma quantidade expressiva de publicações tem se dedicado a esse tema, seja propondo dietas para perder ou ganhar peso, para robustecer músculos, para melhorar a saúde e para diversificar e sofisticar o cardápio, com inúmeras receitas de pratos de regiões do país e também da culinária internacional. Um breve olhar sobre essa produção pode trazer à tona alguns aspectos da alimentação e detectar certas tendências em torno do preparo da comida. Uma, talvez a mais relevante, retira o processamento de alimentos da "cozinha", isto é dos fundos da casa, de sua parte menos nobre, e atribui novo significado a essa prática, dotando-a de valor simbólico mais elevado. Outra tendência é que abre caminho para dessexualizar, pelo menos relativamente, o ato de cozinhar. A culinária deixa de ser, ao me- 
nos na aparência, uma tarefa sexuada, vale dizer feminina, prescrita pela divisão sexual do trabalho e que é uma característica bastante relevante a ser discutida. Em revistas semanais diversas, em jornais de grande circulação, vários homens mostram orgulhosamente suas habilidades culinárias. $\mathrm{O}$ ato de cozinhar converte-se em hobby para esses homens, algo a ser feito em momentos de folga, e é claramente associado a lazer. Além de conquistar um lugar social nobilitado, o preparo de alimentos adquire característica de atividade agradável, repousante, que permite a cada um exercer sua criatividade e exibi-la para amigos em ambiente informal, oposto ao universo estressante e formal do trabalho.

Mas esses "domingueiros da cozinha" não são homens comuns, fazem parte do grupo de privilegiados, das assim chamadas celebridades, que contam com recursos financeiros suficientes para se dedicarem a essa atividade. São artistas de diversos naipes, esportistas, executivos, e a exibição de suas habilidades culinárias procura difundir uma imagem de que a masculinidade pode conviver muito bem na "cozinha", desde que haja sofisticação e requinte nos pratos preparados. Por outro lado, o envolvimento com o ato de cozinhar abre novos mercados destinados ao consumo dos neófitos. Surge uma parafernália de artefatos destinados aparentemente a facilitar o preparo de comida juntamente com livros de receitas, além de programas de televisão comandados por especialistas que ensinam os iniciantes a cozinhar. Alimentação, com tudo que ela envolve, desde a produção até o processamento de alimentos, torna-se um negócio bastante lucrativo para os vários segmentos que produzem artefatos para seu preparo. No entanto, a adesão dos homens à arte de cozinhar, mostra que eles a exercem em ocasiões especiais e que o preparo de alimentos no cotidiano continua a ser tarefa feminina. Como diz um antropólogo ${ }^{1}, \mathrm{o}$ alimento preparado em situações especiais serve para "honrar", é suporte para criação e manutenção de relações sociais e não é destinado apenas a "alimentar", como é a comida do dia-a-dia.

Se o preparo de comida adquire expressiva visibilidade social no presente, o interesse da antropologia pela alimentação tem sido constante, porque ela faz parte de um conjunto de experiências humanas. Desde que Malinowski ${ }^{2}$ desvendou a importância da produção de alimentos e os princípios de sua troca recíproca na sociedade trobriandesa, os trabalhos antropológicos têm dedicado atenção aos inúmeros aspectos da produção, preparo e troca de comida.
No Brasil, já em 1933, quando publicou CasaGrande \& Senzala, Gilberto Freyre ${ }^{3}$ recenseou e registrou não apenas hábitos alimentares, mas inclusive reuniu receitas de vários pratos em seus livros. A produção nacional foi enriquecida com referências sobre o tema nas obras de Candido ${ }^{4}$, Zaluar ${ }^{5}$ e, mais recentemente, com os trabalhos de Woortmann ${ }^{6}$, Murrieta $^{7}$ Menasche ${ }^{8}$, Dutra $^{9}$, Collaço $^{10}$, Topel $^{11}$.

Embora nem sempre ocupe lugar central nos trabalhos antropológicos, a análise de hábitos alimentares aparece associada a temas diversos, sobretudo com ênfase na dimensão simbólica presente na produção de alimentos e no preparo da comida ${ }^{12 / 18}$. Esses trabalhos exemplificam que comida é uma categoria bastante relevante através da qual as sociedades constroem representações sobre si próprias, definindo sua identidade em relação a outras, das quais diferenciam-se nos hábitos alimentares, que constituem elementos significativos para se pensar a identidade social de seus consumidores.

O modo como a antropologia tem tratado a alimentação está vinculado a características nucleares da disciplina. De modo sintético, a primeira delas está relacionada a uma forma de conhecimento, laboriosamente construída para se entender a diversidade dos costumes, mostrando o caráter simbólico que envolve as atividades humanas e como diferentes sociedades organizam de modo particular soluções específicas para resolver problemas universais.

Outro aspecto central na antropologia é que, dentre as ciências sociais, ela é a única que desde seu início tem se proposto a entender a difícil e complexa vinculação entre o natural e o cultural. O natural refere-se a tudo que já é dado pela natureza, inerente à espécie humana e dotado de caráter universal. Um, dentre vários exemplos de necessidades naturais é a fome, que deve ser saciada com a ingestão de alimentos. Se a fome situa-se na esfera do natural e universal, as práticas alimentares, também universais, não são naturais, mas situam-se no campo da cultura. $\mathrm{O}$ conceito de cultura remete a criações humanas simbólicas, produzidas na convivência social e essenciais para se viver em sociedade. Nesse sentido, a cultura é universal pois os seres humanos só conseguem viver através de regras e modelos culturais, isto é, de ordenações socialmente criadas e que constituem sistemas simbólicos organizadores da vida social. Ao mesmo tempo que a cultura tem esse caráter de universalidade, pois todas as sociedades humanas constroem sistemas simbólicos, cada sociedade, ou segmento 
social específico em seu interior, elabora sistemas próprios, diversos, para resolver problemas universais, como a fome.

Esses dois princípios antropológicos permitem balizar e situar algumas questões sobre a alimentação, situada na imbricação da natureza e da cultura. $\mathrm{O}$ ato de saciar a fome é específico de cada sociedade e em torno da comensalidade construíram-se inúmeras regras que fazem parte de um sistema, já que alimentação não é prática isolada, mas integra um sistema simbólico e relaciona-se com outros sistemas. Se todos precisam comer, não o fazem de um mesmo modo.

Os antropólogos têm comparado o impulso para comer com o impulso sexual ${ }^{12,15}$. Lévi-Strauss ${ }^{15}$ assinala a relação, presente em quase todas as línguas do mundo, entre o ato de comer e o de copular. Sexo é fundamental para a reprodução biológica e, como a alimentação, está cercado de tabus, interdições, prescrições que fazem com que o impulso sexual, ele também natural, só possa ser satisfeito observando-se as inúmeras regras que delimitam a escolha de parceiros para o coito. Alimentação e relações sexuais jamais se concretizam no plano da mera naturalidade, ou de uma suposta "animalidade". Se a satisfação do impulso sexual e da fome é essencial para a continuidade da vida humana, relações sexuais e alimentação também partilham outros traços em comum: são fonte de prazer e só se realizam socialmente, sempre dependem da presença de um outro, embora de modo diferenciado, para se realizarem.

Não se pode ter relações sexuais com qualquer pessoa, pois todas as sociedades fixam interdições culturais, das quais a mais importante é a proibição do incesto $^{1}$, que estabelece com quais parceiros não se deve praticar o coito. As penalidades impostas aos infratores são severas e quem mantém relações sexuais com pessoas classificadas como proibidas sofre punições sociais, escárnio e desprezo social. Do mesmo modo, não se pode, nem se deve, ingerir qualquer tipo de comida; quem consome alimentos considerados proibidos, também está sujeito a sanções. Seja pelo escárnio, seja porque a ingestão do que é avaliado como proibido pode excluir o consumidor do rol dos eleitos de determinadas religiões, ou ainda porque pode ocasionar doenças e mesmo a morte.

A alimentação não é ato solitário, mas é atividade social, sempre envolve outras pessoas na produção de alimentos, em seu preparo e, sobretudo, na própria comensalidade, ocasião para se criar e manter formas ricas de sociabilidade. Ressalte-se ainda o as- pecto estético da alimentação, presente na exposição da comida à mesa, na riqueza de formas, cores, odores, bem como a dimensão erótica de alimentos culturalmente classificados como afrodisíacos, supostos estimulantes do desejo e do aprimoramento da performance sexual. Assim, a alimentação só pode ser entendida como processo social complexo que envolve diferentes esferas da vida social, inclusive a dimensão do sagrado.

\section{2- A DIMENSÃo SIMBÓLICA E AS REGRAS DIETÉTICAS}

$\mathrm{O}$ ato de alimentar-se é sempre mediado por regras dietéticas, cujas origens e finalidades são múltiplas e são elaboradas a partir de diversas formas de saber, como o conhecimento científico, o senso comum, as religiões, que criam interdições para excluir do cardápio alimentos considerados culturalmente como nocivos.

As grandes religiões monoteístas sempre se preocuparam em seus livros sagrados em estabelecer tabus alimentares delimitando o que os fiéis podem ou não comer. Regras dietéticas estão presentes na Bíblia, no Levítico e no Deuteronômio, classificando os animais em puros e impuros, permitidos ou proibidos para consumo. Assim, pode-se comer animais que têm unha fendida dividida em duas e que ruminam, como boi, ovelha, cabra; mas são impuros e impróprios para o consumo aqueles que só apresentam uma dessas características, como camelo, lebre, porco, com unha fendida, mas que não são ruminantes. Dos que vivem na água são comestíveis aqueles com barbatanas e escamas, mas são imundos os que não têm essas duas características. Essas interdições, analisadas por Douglas ${ }^{18}$, estão relacionadas à idéia de santidade, de integridade. A raiz de "santidade" significa "colocar separadamente", estabelecer a ordem correta, fundada no sagrado. Os tabus alimentares visam separar alimentos cuja ingestão pode poluir quem os consome. Para Douglas ${ }^{18}$, a noção de poluição, de sujeira, não está relacionada a questões de higiene, tampouco visa proibir a utilização de alimentos que representem ameaça à higidez. As proibições do consumo de determinados alimentos não pretendem proteger o "organismo biológico", mas objetivam defender o "organismo social" dos membros de determinado grupo religioso, fixando suas identidades em contraponto às identidades de participantes de outros grupos religiosos. Essas regras dietéticas não têm apenas caráter 
prático, fundado no conhecimento acerca das propriedades dos alimentos, mas fazem parte de um sistema simbólico mais amplo, ancorado na idéia de sagrado, que estabelece fronteiras entre judeus e gentios.

A análise de Douglas ${ }^{18}$ evidencia que por trás da aparente racionalidade das regras dietéticas judaicas, encontra-se um complexo sistema simbólico. É nesse sentido que a antropologia submete à interrogação a concepção ocidental de que atos humanos estão fundados em uma racionalidade só acessível através do conhecimento formulado cientificamente. A análise das regras dietéticas judaicas, bem como de normas alimentares de outras religiões, revela que seu fundamento não se encontra no materialismo médico, mas essas regras constituem um sistema simbólico dedicado a estabelecer padrões normativos que tomam a comida como categoria relevante para estabelecer as identidades sociais de seus consumidores.

Não basta ter acesso ao saber científico para modificar costumes alimentares, pois eles não estão fundados tão somente na racionalidade humana. Esta certamente existe, mas convive tensamente com valores simbólicos e com os prazeres propiciados pela comida, sejam eles gustativos, psicológicos ou sociais, isto é, provenientes das relações criadas em torno das refeições. De fato, a humanidade come de tudo; inclusive a si própria, como mostra a prática do canibalismo. Neste caso, ingerir o corpo do outro pode representar uma maneira de tê-lo simbolicamente perto de si e de superar a dor do luto e da perda.

\section{3- AFETO E COMENSALIDADE}

O caráter social da alimentação está presente desde o nascimento. O leite materno é o primeiro alimento oferecido ao ser humano e sua ingestão envolve o contato com o corpo da mãe, mediado pelo seio. Por isso, desde o início da vida humana a alimentação está associada tanto a afeto e proteção quanto seu preparo está indelevelmente ligado ao universo feminino. Essa estreita vinculação prossegue durante a existência humana devido à divisão sexual do trabalho, segundo a qual o processamento de refeições constitui tarefa da mulher. Devido às representações negativas que incidem indevidamente sobre as atribuições domésticas, basicamente realizadas por mulheres, incluindo-se nelas as atividades culinárias, essas tarefas são consideradas menos dignas do que o trabalho masculino, o que contribui para deixar de lado a investigação mais acurada do preparo de alimentos.
A dimensão afetiva da alimentação, que engloba a relação com o outro, está presente nas refeições familiares, momentos de encontro, de conversação e de troca de informações, isto é, da criação e manutenção de formas de sociabilidade bastante ricas e prazerosas. Certamente o repasto familiar jamais se caracteriza unicamente pela positividade de relações harmoniosas e de solidariedade. Ao contrário, pode constituir cenário para disputas intensas entre comensais. Contudo, essa dicotomia é constitutiva de todas as relações sociais e harmonia não elimina a presença do conflito e vice-versa.

No entanto, hoje almoça-se principalmente com amigos, com colegas de trabalho, ou com desconhecidos que se sentam à mesma mesa. Nesse último caso, a sociabilidade durante as refeições quase desaparece, mas pode ser momento para entrar em contato com quem se partilha a mesa e para dar início à conversação, mesmo que seja transitória e limitada àquele momento.

Lévi-Strauss ${ }^{1}$ descreve essa ocasião de encontro. Em pequenos restaurantes franceses, quando dois desconhecidos dividem a mesma mesa, um oferece ao outro a pequena garrafa de vinho destinada a seu consumo. $\mathrm{O}$ alimento é escolhido por cada um, mas o vinho tem caráter simbólico distinto e não deve ser usufruído individualmente. A norma de etiqueta pressupõe que oferecer o conteúdo de sua garrafa, que contém a mesma quantidade e o mesmo vinho, para o parceiro diante de si é propício para romper a barreira do isolamento e para dar início à relação com o outro.

\section{4- ALIMENTAÇÃo, FAMÍliA E POBREZA}

A comida é uma categoria através da qual os pobres pensam sua relação com os "ricos" que não enfrentam necessidades alimentares e com os muito pobres, que passam fome. Desse modo, a categoria comida estabelece fronteiras entre a identidade de pobres, dos ricos e dos muito pobres.

Para a população de baixa renda os alimentos são classificados entre os que são comida, como arroz, feijão, carne. Em suas representações são alimentos "fortes" que sustentam e se contrapõem a verduras, legumes, frutas que servem para "tapear" e são indicados no diminutivo como "coisinhas", "saladinhas", "verdurinhas" que não enchem barriga 5 .

Essa lógica classificatória não se funda no valor nutriente dos alimentos, mas no fato de que proporcionam a sensação de repleção, pois são gorduro- 
sos ou preparados com gordura animal e demoram para ser digeridos, dando a sensação de "barriga cheia". Não se trata de desconhecimento do valor nutritivo de frutas e legumes, mas da suposição, demonstrada na prática, de que eles não proporcionam a sensação de repleção e que seu consumo deixa a sensação de fome ${ }^{5}$. A dieta da população pobre é monotonamente repetida, menos por falta de conhecimento do que pelo significado que os alimentos considerados "fortes" ocupam no sistema classificatório alimentar, bem como pelas condições socioeconômicas em que vivem. Muito provavelmente, a mesma monotonia freqüenta o cardápio daqueles qualificados como "ricos".

Fazer com que os filhos habituem-se às normas alimentares das famílias pobres é um processo complicado que mobiliza as mães. Os filhos revelam preferência por alimentos diferentes daqueles presentes em suas casas, classificados justamente como guloseimas, tais como doces, bolachas, refrigerantes ${ }^{5}$. Esses produtos são considerados mais saborosos, além de serem dotados de valor simbólico diverso, estando associados ao universo alimentar dos "ricos".

Por sua vez, as mulheres tendem a reservar a melhor parte do que preparam para os maridos quando eles levam a refeição para o local de trabalho. Essa postura é um recurso para mostrar que a família não vive em situação de grande precariedade material e para que o marido não "passe vergonha" diante dos outros ${ }^{19}$. Essa conduta feminina demonstra outra forma de os pobres utilizarem a comida como demonstração pública da posição social da família e que suas condições não são tão precárias.

As regras alimentares dos pobres convivem com normas dietéticas de cunho médico-científico que adquiriram hegemonia, difundindo-se para todos os segmentos sociais da população. Mas hegemonia não significa exclusão de outras regras alimentares. Como todo produto cultural, as normas dietéticas não são absorvidas, incorporadas e postas em prática do mesmo modo, mas convivem com outras ordenações culturais de modo ambíguo e conflitante. Além disso, interesses mercantis mobilizam-se para difundir, promover e incentivar o consumo de determinados alimentos, sobretudo do supérfluo, daquilo que a população de baixa renda chama de "guloseimas", destinadas especialmente a crianças e adolescentes.

Em sua dimensão sociocultural alimentar-se é um meio de marcar identidades, de estabelecer fronteiras entre segmentos sociais. Oferecer aos filhos alimentos pouco nutritivos constitui um meio de a popu- lação pobre mostrar para si mesma e para seus iguais que ela também pode consumir o que é simbolicamente positivo. Ainda no plano da sociabilidade familiar a possibilidade de consumo de tais produtos aparece associada à dimensão afetiva, isto é, oferecer o que não é fundamental para a alimentação traduz-se para pais e filhos em demonstração de afeto, mesmo que à custa da contenção da aquisição de outros bens, às vezes mais necessários para a família como um todo.

Ora, as mulheres ocupam uma posição fundamental na alimentação da família por vários motivos. Elas controlam, se não o orçamento doméstico, pelo menos as compras de alimentos, seu processamento, socializam os filhos para aceitá-los e distribuem a comida entre os componentes da família. Mais importante ainda, é que as mulheres têm maior acesso do que os homens a informações acerca da alimentação, provenientes de várias fontes e de programas diversos de orientação. As mulheres são mediadoras entre universos nos quais predominam regras alimentares diversificadas e podem ser agentes transformadores de hábitos alimentares.

A população de baixa renda enfrenta falta de recursos financeiros para ter acesso a certos tipos de alimentos. Mas não é sua suposta ignorância que impede o consumo de produtos adequados e de baixo custo. De modo geral, há um vasto rol de informações circulando entre as famílias pobres. Mas elas enfrentam dificuldade em substituir hábitos solidamente implantados ou para adequá-los ao saber científico, pois esses hábitos fazem parte de um sistema, onde cada item ocupa um lugar que faz "sentido", pois está integrado em um corpo de saberes. Torna-se difícil encaixar novas orientações porque as regras alimentares estão incorporadas na interioridade dos sujeitos e encapsuladas pelo aspecto afetivo e pelo prazer que proporcionam.

O grande dilema de todos os profissionais da área de saúde que trabalham com essas questões é que eles se defrontam com a realidade cultural da população pobre, diversa daquela produzida pelo conhecimento científico, de que esses agentes são portadores.

No entanto, a convivência entre códigos culturais conflitantes não ocorre apenas entre a população pobre, queixa comum dos profissionais da área. Está presente com toda força e intensidade no seio das camadas médias, que desfrutam de maior acesso ao conhecimento científico, em função de escolaridade mais elevada e de condições financeiras para se alimentarem de acordo com padrões considerados adequados. 
Para tomar alguns exemplos do modo de relacionamento com a comida, temos os casos de anorexia, bulimia, obesidade, úteis para explicitar que a relação com a comida nunca é direta, ou melhor, nunca é determinada em função da qualidade dos alimentos e de sua função para a saúde. Esses exemplos revelam ainda que não basta ter acesso ao conhecimento acerca das propriedades dos alimentos, mas que a relação com eles não é dada pelas necessidades do organismo, ou pela racionalidade do conhecimento médico-científico, mas é mediada por um complexo sistema simbólico que organiza escolhas alimentares.

Essas considerações podem alertar aqueles que tratam diretamente com a população pobre de que seres humanos não são plenamente racionais, mas são antes de tudo animais bastante complexos e complicados, que não se sujeitam a seguir obedientemente or- denações de cunho científico. Antes de considerar as escolhas alimentares como fruto de uma irracionalidade que atinge apenas alguns, como pobres, anoréxicos, bulímicos, obesos e outros, seria melhor pensar nessas escolhas como possibilidades sempre presentes para a espécie humana. Não é apenas no plano alimentar que os homens rebelam-se contra o instituído, e que além de instituído é considerado adequado, saudável, racional. Nas mais diversas esferas da vida social sempre há os rebeldes que, ao não acatarem o estabelecido, contribuem para desafiar o conhecimento e para propor alternativas culturais diversas a fim de resolver problemas que são comuns a todos. É no plano da rebeldia, da recusa a normas, regras, valores instituídos que se reproduz a diversidade cultural, o que cria um espectro amplo de possibilidades para se viver em sociedade.

Romanelli G. The meaning of alimentation in family: an anthropological view. Medicina (Ribeirão Preto) 2006; 39 (3): 333-9.

ABSTRACT: Hunger is a natural need that must be satisfied through the ingestion of food in order to ensure the production and reproduction of human existence. However, if appeasing hunger is a natural and universal action, alimentation practices are also universal. They are not natural, but are situated in the scope of culture, that is to say, in the field of symbolic systems. Around commensality, each society designs a complex system of dietetic rules based on common sense, religious precepts and medical knowledge, which creates interdictions to exclude foods that are symbolically classified as harmful or dangerous to health from its menu. Anthropological studies have shown the diversity of alimentary practices, which do not constitute a solitary act, but are social activities including the production, processing and consumption of food and how societies construct their own representations, thus defining their identity in relation to other societies through their eating habits. This study examines how the low-income population articulates symbolic elements from various sources in order to organize dietetic rules that eventually become cultural indicators through which food is categorized as appropriate or harmful for consumption. Food is a category that establishes boundaries between the identity of the poor population, who faces difficulty to promote alimentation, and the identity of those whose culinary is rich and varied and that of the very poor, who starve.

Keywords: Feed. Dietetic; rules. Family; low-income.

\section{REFERÊNCIAS}

1 - Lévi-Strauss C. Les structures eléméntaires de la parenté. $2^{\mathrm{a}}$ ed. Paris: Mouton; 1973.

2 - Malinowski B. Argonautas do Pacífico Ocidental. Um relato do empreendimento e da aventura dos nativos nos arquipélagos da Nova Guiné melanésia. São Paulo: Abril Cultural; 1984.
3 - Freyre G. Casa-Grande \& Senzala. 10ª ed. Rio de Janeiro: José Olympio; 1961.

4 - Candido A. Os parceiros do Rio Bonito. $2^{a}$ ed. São Paulo: Duas Cidades, 1971.

5 - Zaluar A. As mulheres e a direção do consumo doméstico. In: Almeida MSK et al. Colcha de retalhos. Estudos sobre a família no Brasil. São Paulo: Brasiliense; 1982. p. 159-84. 
6 - Woortmann K. A comida, a família e a construção do gênero feminino. Dados 1986; 29 (1): 103-30.

7 - Murrieta RSS. O dilema do papa-chibé: consumo alimentar, nutrição e práticas de intervenção na llha de Ituqui, baixo Amazonas, Pará. Rev Antropol 1998; 41 (1): 1-22.

8 - Menasche R. Risco à mesa: alimentos transgênicos, no meu prato não? Campos 2004; 5(1): 111-29.

9 - Dutra RC de A. Nação, região, cidadania: a construção das cozinhas regionais no projeto nacional brasileiro. Campos 2004; 5(1): 93-110.

10 - Collaço JHL. Um olhar antropológico sobre o hábito de comer fora. Campos 2003; 4: 171-94.

11 - Topel, MF. As leis dietéticas judaicas: um prato cheio para a antropologia. Horiz Antropol 2003; 9: 203-22.

12 - Mintz SW. Comida e antropologia. Uma breve revisão. Rev Brasil Ci Soc 2001; 16 (47): 31-41.
13 - Lévi-Strauss C. Le cru et le cuit. Paris: Plon; 1964.

14 - Lévi-Strauss C. L'origine des manières de table. Paris: Plon; 1968.

15 - Lévi-Strauss C. A lição de sabedoria das vacas loucas. Estud CEBRAP 2004; 70: 79-84.

16 - Sahlins MD. Cultura e razão prática. Rio de Janeiro: Zahar; 1979.

17 - Harris M. Vacas, porcos, guerras e bruxas: os enigmas da cultura. Rio de Janeiro: Civilização Brasileira; 1978.

18 - Douglas, M. Purity and danger. An analysis of concepts of pollution and taboo. London: Routledge \& Kegan Paul; 1966.

19 - Fausto Neto AMQ. Família operária e reprodução da força de trabalho. Petrópolis: Vozes; 1982. 